\title{
Concanavalin A-Induced T-Cell-Mediated Hepatic Injury in Mice: The Role of Tumor Necrosis Factor
}

\author{
Florian Gantner, ${ }^{1}$ Marcel Leist, ${ }^{1}$ Ansgar Wilhelm Lohse, ${ }^{2}$ Paul Georg Germann, ${ }^{3}$ and Gisa Tiegs ${ }^{1}$
}

\begin{abstract}
Concanavalin $A$ activates $T$ lymphocytes in vitro and causes $T$-cell-dependent hepatic injury in mice. $T$ lymphocytes were previously identified as effector cells of concanavalin A-induced liver injury. Here we report that hepatic injury is characterized by apoptotic cell death. On concanavalin A challenge, the cytokines tumor necrosis factor- $\alpha$ (INF $\alpha$ ), interleukin-2, granulocyte macrophage-colony stimulating factor, and interferon$\gamma$ were detectable in the circulation of the mice. Pretreatment of mice with anti-mouse TNF- $\alpha$ antiserum protected them from concanavalin A-induced liver injury. Nude mice failed to release TNF- $\alpha$ or interleukin-2 after concanavalin $A$ challenge and were protected from liver injury. Lymph node cell transfer from responder mice to resistant nude mice resulted in susceptibility of the latter towards concanavalin $A$, i.e., to induction of cytokine release and hepatotoxicity. These experiments suggest that immunocompetent $T$ cells play a pivotal role in concanavalin A-stimulated TNF- $\alpha$ release in vivo. After intravenous administration of fluorescein isothiocyanate-labeled concanavalin A to mice, the most fiuorescence was found within the liver. In vitro, concanavalin A stimulation of separate cultures of mouse lymph node cells or nonparenchymal liver cells induced the release of minute amounts of TNF, whereas stimulation of cocultures of these cells resulted in production of substantial amounts of TNF- $\alpha$. These findings may explain the hepatotropic effect of concanavalin $A$. In conclusion, T-celldependent concanavalin A-induced apoptotic liver injury in mice is related to immunological and cytokinemediated disorders and possibly to autoreactive hepatic processes.
\end{abstract}

Abbreviations: IL, interleukin; IFN- $y$, interferon gamma; GM-CSF, granulocyte macrophage-colony stimulating factor; TNF, tumor necrosis factor; OKT3, orthoclone T3 antibodies; Con A, concanavalin A; SCID, severe combined immunodeficiency syndrome; FITC, fluorescein isothiocyanate; NMRI, Naval Medical Research Institute; PBS, phosphate-buffered saline; ELISA, enzyme-linked immunosorbent assay; LNC, lymph node cell; ALT, alanine aminotransferase; Ig, immunoglobulin; EDTA, ethylenediaminetetraacetic acid; NPC, nonparenchymal cell; BCG, bacille Calmette-Guérin; EAE, experimental allergic encephalomyelitis.

From the ${ }^{1}$ Faculty of Biology, University of Konstanz, Konstanz, Germany; ${ }^{2}$ Medizinische Klinik und Poliklinik, Johannes Gutenberg-Universität, Mainz, Germany; and ${ }^{3}$ Institute of Pathology and Toxicology Byk Gulden, Hamburg, Germany.

Supported by the Deutsche Forschungsgemeinschft grant no. Ti 169/3.

Address reprint requests to: Gisa Tiegs, MD, Faculty of Biology, University of Konstanz, POB 5560, D-78434 Konstanz, Germany.
In mammalian organisms suffering from viral infection, allograft rejection, or autoimmune diseases, $T$ lymphocytes serve as effector cells of the immunostimulatory processes. With respect to human liver disease, viral hepatitis, and at least three autoimmune syndromes, i.e., primary biliary cirrhosis, chronic active hepatitis, and primary sclerosing cholangitis are clinically relevant. ${ }^{1} \mathrm{~T}$-cell activation results in production of cytokines such as interleukin (IL)-2, interferon gamma (IFN- $\gamma$ ), granulocyte macrophage-colony stimulating factor (GM-CSF), and tumor necrosis factors (TNF). This cytokine production maintains the immunostimulatory and inflammatory processes and may evoke acute toxicity. ${ }^{2}$ For instance, administration of T-cellactivating orthoclone T3 antibodies (OKT3) directed against the signal transducing CD3 molecule of T cells to allograft recipients results in clinical symptoms, such as fever, chills, tremor, dyspnea, chest pain, wheezing, and gastrointestinal complications, ${ }^{3}$ before subsequent T-cell inactivation and depletion. Pharmacological suppression of TNF production abrogated the side effects of OKT3 administered to patients who underwent renal transplantation. ${ }^{4,5}$ In an experimental mouse model a monoclonal anti-CD3 antibody induced massive systemic release of cytokines, such as TNF, IL2 , and IFN- $\gamma$, and led to severe sinusoidal congestion of the liver, hepatocyte vacuolization and focal hepatic necrosis. ${ }^{6}$ Another group of extremely potent T-cellactivating molecules are enterotoxins of gram-positive bacteria. ${ }^{7}$ These molecules, also termed superantigens, account for at least $45 \%$ of food poisoning ${ }^{8}$ and may cause toxic shock ${ }^{9}$ and autoimmune diseases. ${ }^{10,11}$ Enterotoxins were shown to induce the release of cytokines in vivo. Anti-TNF antibodies protected against enterotoxin-induced lethal shock in D-galactosaminesensitized mice. ${ }^{2}$

We recently described an experimental liver injury model in mice that is inducible by concanavalin A (Con A), ${ }^{12}$ a plant lectin from jack bean (Canavalia ensiformis) known to mitogenically activate $\mathrm{T}$ lymphocytes in vitro. Lectin-induced lymphocyte proliferation in vitro is accompanied by the production of lymphokines and monokines, i.e., by lymphocyte-derived and monocyte-derived cytokines. ${ }^{13}$ Our previous results showed that intravenous administration of Con A to mice resulted in T-cell stimulation and IL-2 release in vivo. ${ }^{12}$ Con $\mathrm{A}$-induced T-cell activation led to induction of a 
highly specific single organ failure, i.e., to liver injury, within 8 hours after challenge. Hepatic injury was assessed by electron microscopy of the organ and by determination of plasma transaminases as well as of plasma levels of the liver-specific enzyme sorbitol dehydrogenase. Immunosuppressive drugs, such as Ciclosporin A, FK506 (Fujimycin, Osaka, Japan), or corticosteroids, prevented this experimental liver failure. Immunodeficient mice, i.e., mice with severe combined immunodeficiency syndrome (SCID mice) or athymic nude mice failed to develop hepatitis on Con A challenge. Cell depletion experiments identified CD4 ${ }^{+} \mathrm{T}$ cells as well as macrophages as effector cells in this model. We now report that Con A causes systemic release of cytokines such as TNF- $\alpha$, GM-CSF, IL-2, and IFN- $\gamma$. Neutralization of TNF- $\alpha$ abrogated the fatal outcome of Con A challenge. It is concluded that Con A induces hepatic injury mediated by cytokines such as TNF- $\alpha$. Histological examination gives evidence for apoptosis as a possible mechanism of hepatocyte cell death induced by Con $\mathrm{A}$ in vivo. Possible explanations of the hepatotropic effect of Con A are suggested by the finding that the majority of intravenously administered fluorescein isothiocyanate (FITC)-labeled Con A was found within the liver and by the outstanding capacity of lymphocyte/nonparenchymal liver cell cocultures to release substantial amounts of TNF- $\alpha$ on in vitro stimulation by Con A.

\section{MATERIALS AND METHODS}

Animals. Male Naval Medical Research Institute (NMRI) albino mice and male nude NMRI albino mice were from the Hannoversches Zentralinstitut, Hannover, Germany. Male $\mathrm{BALB} / \mathrm{c}$ mice were from the animal house of University of Konstanz, Germany. All mice were kept at least 1 week at $22^{\circ} \mathrm{C}$ and $55 \%$ relative humidity in a 12-hour day/night rhythm with free access to food (Altromin 1313) and water. Sixteen hours before the experiment food was withdrawn, and mice were not fed overnight. All animals received humane care in compliance with the guidelines of the head of the Regierungsbezirk Freiburg, Germany.

Treatment Schedules. Con A was purchased from Sigma Chemical Co, St. Louis, MO, and $20 \mathrm{mg} / \mathrm{kg}$ were administered intravenously in a volume of $300 \mu \mathrm{L}$ of pyrogen-free phosphate-buffered saline (PBS).

FITC-labeled Con A (Sigma Chemical Co, St. Louis, MO) was injected at the same dose as above $(20 \mathrm{mg} / \mathrm{kg})$ into the tail vein. Animals were killed 30 minutes after injection, and livers as well as control organs (kidneys, lungs, heart, bowel, muscle, and pancreas) were removed and immediately frozen in liquid nitrogen. Frozen tissue was divided into sections using a microtome (Leitz, Wetzlar, Germany) and was assessed under a fluorescence microscope (Olympus IMT/2, Olympus, Hamburg, Germany).

Polyclonal sheep anti-mouse TNF- $\alpha$ antiserum was intravenously administered 15 minutes before Con A challenge in a dose of $10 \mu \mathrm{L}$ per mouse $(30 \mathrm{~g})$. This antiserum did not display cross-reactivity to mouse IL-1, IL-2, IL-4, IL-6, IL10 , IFN- $\gamma$, G-CSF and GM-CSF as tested in bioassays (see below) or in commercially available enzyme linked immunosorbent assay (ELISA) (Pharmingen, San Diego, CA), respectively.

For transfer experiments, male nude NMRI (nude/nude)

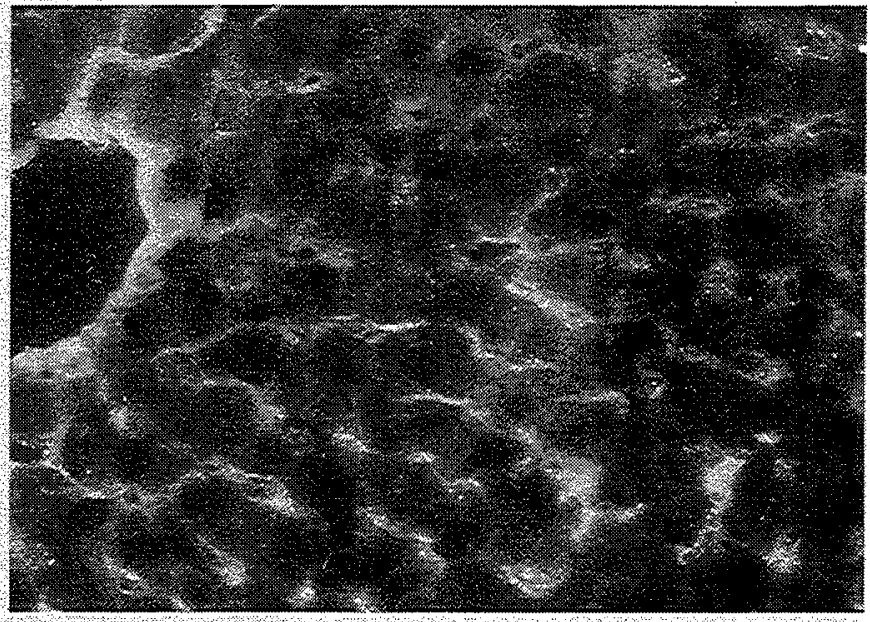

FIG. 1. Binding of FITC-labeled Con A in mouse liver. Frozen tissue section $(\times 800)$ of a BALB/c mouse liver removed 30 minutes after injection of $20 \mathrm{mg} / \mathrm{kg}$ FITC-labeled Con $A$ into the tail vein and assessed under a fluorescence microscope. Linear staining along endothelial surfaces can be observed. No such staining was observed in other organs.

mice were injected intravenously (IV) 7 days before Con A challenge with $2.5 \times 10^{7}$ lymph node cells (LNC) isolated from male NMRI albino mice.

Ciclosporin A (Sandimmune, Sandoz, Basel, Switzerland) was IV administered twice at doses of $130 \mathrm{mg} / \mathrm{kg}$ each 15 hours and 1 hour, respectively, before Con A challenge. Mice injected with the corresponding volumes of the diluent (Sandimmune, placebo) were examined as controls.

Blood sampling from the tail vein for TNF-determination or IL-2-determination was performed 1.5 or 4 hours after Con A administration, respectively. Eight hours after Con A challenge, mice were killed by cervical dislocation. Blood was withdrawn by heart puncture into heparinized syringes. The extent of liver injury was assessed by determination of plasma alanine aminotransferase (ALT) activity according to Horder. ${ }^{14}$

For determination of the time courses of cytokine release into the circulation after Con A challenge, mice were killed at the time points indicated, and blood withdrawn by heart puncture was collected in heparinized syringes.

Cytokine Assays. GM-CSF and IFN- $\gamma$ were determined using a commercially available ELISA kit from Endogen, Boston, MA, and from Gibco RBL, Gaithersburg, MD, respectively. TNF was measured in a bioassay using the murine fibrosarcoma cell line WEHI 164 clone 13 according to Espevik and Nissen-Meyer. ${ }^{15}$ IL-2 was determined in a cell proliferation assay according to Tada et $a l,{ }^{16}$ with the modification of using the mouse cytotoxic T-cell line CTLL-2. IL-1 was determined, according to Hopkins and Humphreys, ${ }^{17}$ using a cellular assay based on the IL-1-dependent proliferation of the murine T-helper cell line D10N. Cytokine concentrations determined in the bioassays were calculated by the use of murine standards, specificity was obtained by coincubation with the respective antibodies (monoclonal anti-mouse IL$1 \alpha$, monoclonal anti-mouse IL- $1 \beta$, monoclonal anti-mouse IL2 antibodies, all from Genzyme, Cambridge, MA, and polyclonal sheep anti-mouse TNF- $\alpha$ antiserum from our laboratory).

The polyclonal rabbit anti-human TNF- $\beta$ antibody $(80 \%$ immunoglobulin G (IgG), 20\% immunoglobulin M (IgM), Gen- 

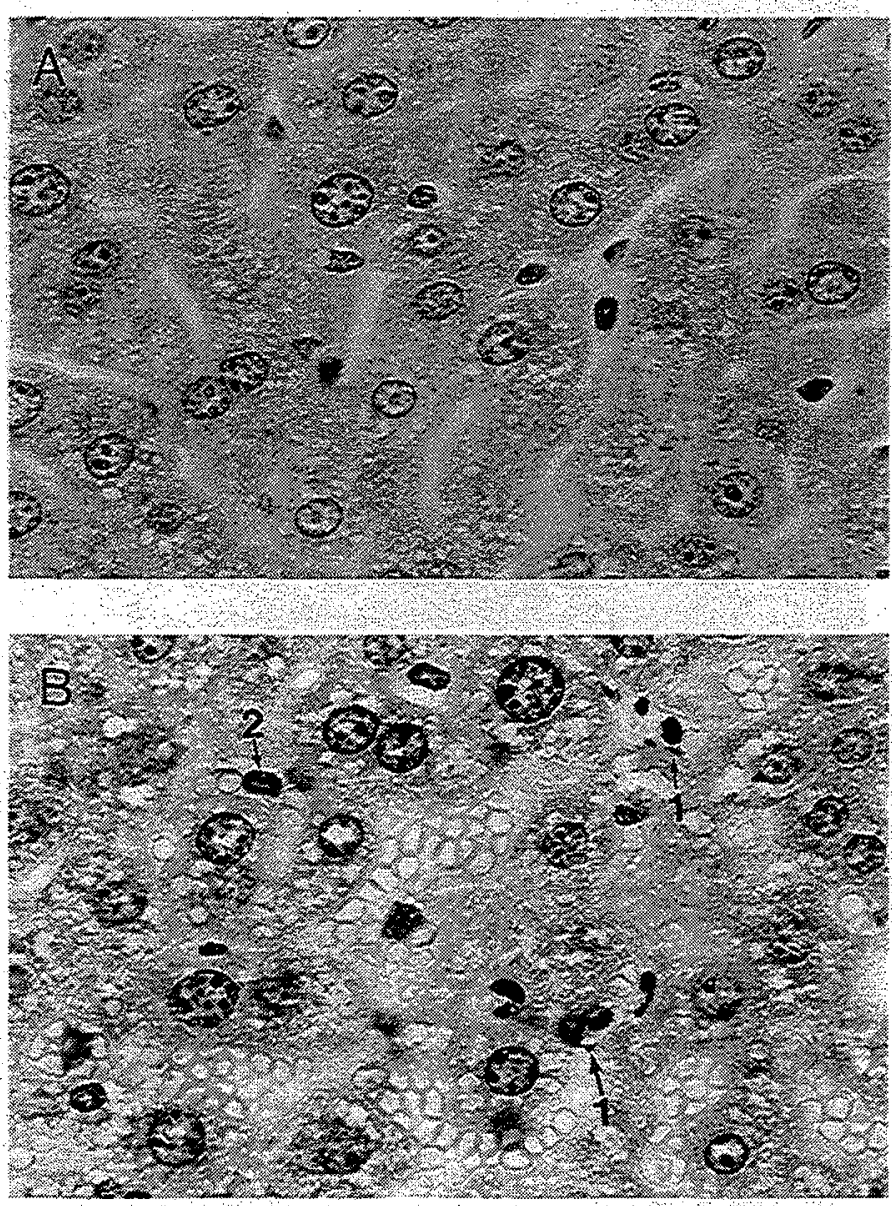

FIG. 2. Histological alterations in mouse livers 8 hours after challenge with $20 \mathrm{mg} / \mathrm{kg}$ Con A. A small piece from the large median lobe was fixed by immersion in Carnoy's solution after blood-free perfusion of the liver. Five- $\mu \mathrm{m}$ sections were stained with $\mathrm{HE}$ and photographed at $1008 \times$ original magnification. (A) Liver from a saline-treated control mouse. No histological abnormalities are detectable. (B) Liver from a Con A-treated mouse. A moderate diffuse cloudy swelling is evident in the hepatocellular cytoplasm. Numerous apoptotic bodies are visible (1). Severe agglutination of erythrocytes accompanied by an infiltration of liver sinusoids with neutrophilic granulocytes (2) is detectable.

zyme, Cambridge, MA) shows approximately $70 \%$ cross-reactivity with mouse TNF- $\beta$ (data provided by the supplier).

Microscopy. Mice were anesthetized by pentobarbital (100 $\mathrm{mg} / \mathrm{kg}$ ). Livers were perfused for 10 seconds with cold buffer (50 $\mathrm{mmol} / \mathrm{L}$ phosphate, $120 \mathrm{mmol} / \mathrm{L} \mathrm{NaCl}, 10 \mathrm{mmol} / \mathrm{L}$ ethylenediaminetetraacetic acid (EDTA) pH 7.4). One liver lobe was excised and fixed for histological examination with Carnoy's solution and imbedded in paraplast. Five-micrometer sections were stained with hematoxylin-eosin (HE) and photographed at 1,008-fold magnification.

Cell Preparations for Coculture Experiments. Spleen or lymph nodes (axillary, brachial, iliac, inguinal, facial, and superior mesenteric) from $B A L B / c$ mice were removed and ground through a steel grid (diameter $100 \mu \mathrm{m}$ ) into $5 \mathrm{~mL}$ Roswell Park Memorial Institute 1640 medium (Biochrom, Berlin, Germany). Ex vivo cytokine determination was carried out directly from the supernatants of spleen cell suspensions after centrifugation at $400 \mathrm{~g}$ for 8 minutes. $10^{6} \mathrm{LNC}$ were cocultured with either parenchymal or nonparenchymal liver cells in a volume of $200 \mu \mathrm{L}$ in 24 well plates and incubated at $37^{\circ} \mathrm{C}, 5 \% \mathrm{CO}_{2}$, and $40 \% \mathrm{O}_{2}$ with or without Con $\mathrm{A}$ $(2 \mu \mathrm{g} / \mathrm{mL})$. Supernatants were frozen at $-70^{\circ} \mathrm{C}$ until cytokine determination.

Hepatocytes were isolated from 12-week-old male BALB/c mice by the two-step collagenase perfusion method of Seglen ${ }^{18}$ as modified by Klaunig et al. ${ }^{19}$ Hepatocytes were plated in $200 \mu \mathrm{L}$ RPMI 1640 medium containing $10 \%$ newborn calf serum (NCS, Biochrom, Berlin, Germany) in 24 well plates at a number of $8 \times 10^{4}$ hepatocytes per well. Cells were allowed to adhere to culture plates for 5 hours before the medium was exchanged for RPMI 1640 medium or RPMI 1640 medium containing LNCs. Incubations were performed for the times indicated in an incubator run at $5 \% \mathrm{CO}_{2}, 40 \% \mathrm{O}_{2}$ and $55 \% \mathrm{~N}_{2}$. Hepatocyte cultures contained 5\% Kupffer cells as determined by latex phagocytosis.

Nonparenchymal cells (NPC) were purified by differential
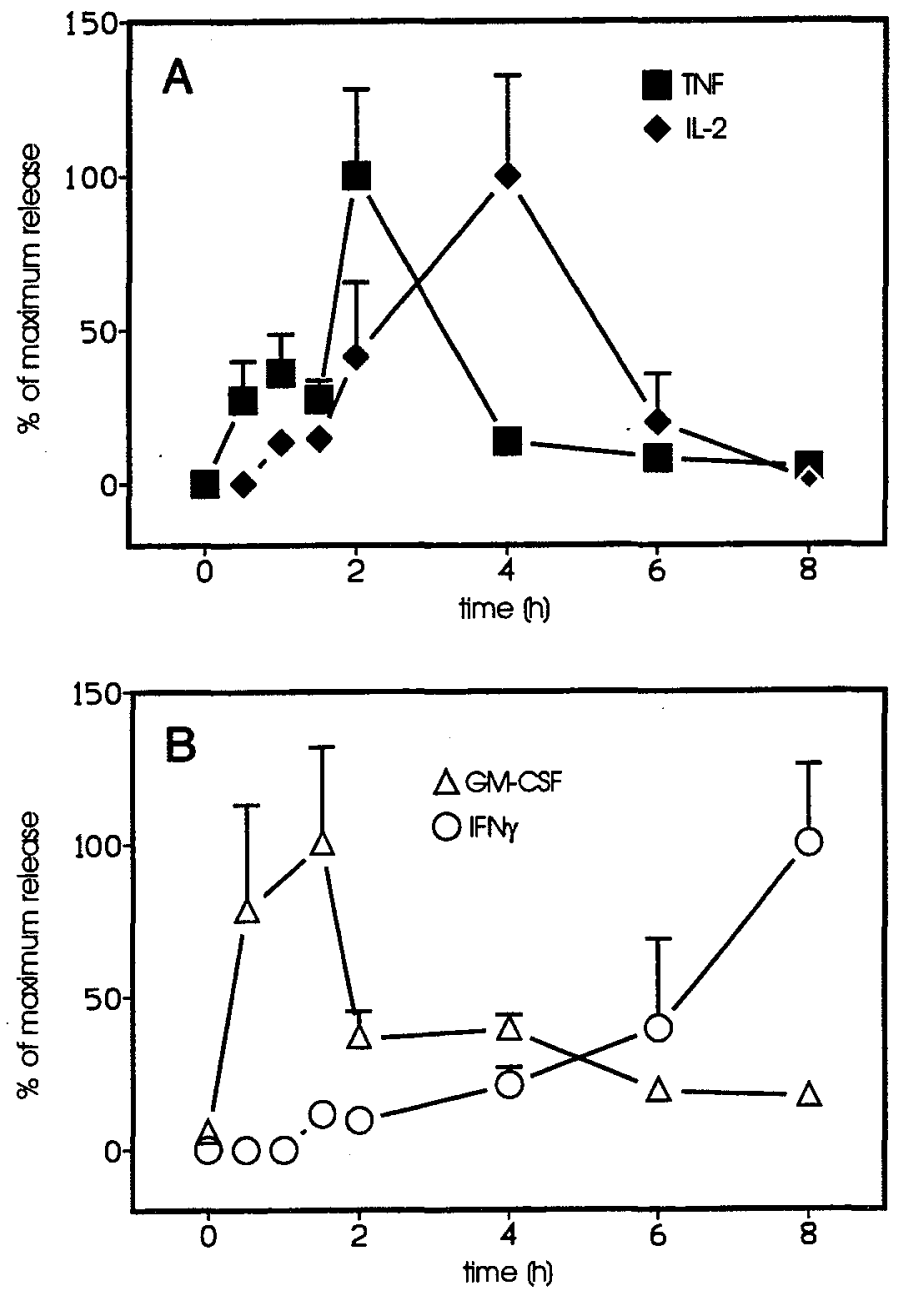

FIG. 3. Time course of cytokine release into plasma of NMRI mice challenged by $20 \mathrm{mg} / \mathrm{kg}$ Con $\mathrm{A}$ intravenously at time point zero (h). Each time point represents a group of three animals, respectively. Data are given as percentage of the individual maximum concentrations \pm SEM. These maxima were (A) TNF, $2,500 \pm 690 \mathrm{pg} /$ $\mathrm{mL}, \mathrm{IL}-2,34,600 \pm 11,200 \mathrm{pg} / \mathrm{mL}$, and (B) GM-CSF, $300 \pm 90 \mathrm{pg} /$ $\mathrm{mL}$, IFN- $\gamma 2,770 \pm 1,200 \mathrm{pg} / \mathrm{mL}$. None of the four cytokines was detectable in plasma of control animals. 
centrifugation from the liver cell suspension after collagenase digest according to Hartung and Wendel. ${ }^{20}$ Briefly, supernatants from two successive $100 \mathrm{~g}$ centrifugations of hepatocytes were pooled and centrifuged for 8 minutes at $400 \mathrm{~g}$. The pellet contained the NPC fraction. NPC were washed twice and plated out at $2 \times 10^{5}$ cells/well in $200 \mu \mathrm{L} \mathrm{RPMI} 1640+10 \%$ NCS. After a plastic adherence phase of 3 hours, supernatants were discarded and exchanged for RPMI 1640 or RPMI 1640 containing LNCs. After the adherence step, $1 \times 10^{5}$ NPC stuck to the culture plate, containing $80 \%$ to $90 \%$ Kupffer cells and no hepatocytes as determined by unspecific esterase stain and latex phagocytosis.

Statistics. The results were analyzed according to the Student's t-test or to the Welsh test. Data are expressed as mean values $\pm \mathrm{SEM} ; P<.05$ was considered to be significant.

\section{RESULTS}

Organotropy of FITC-Labeled Con A In Vivo. Thirty minutes after injection of FITC-labeled Con A, significant fluorescence was only noted within the liver (Fig. 1). No specific staining was observed in pulmonary or renal tissue or any of the other organs examined. The fluorescence staining in the liver appeared to be linear along the endothelial surfaces of the liver sinusoids. Uptake of FITC-labeled Con A by hepatocytes was not observed. Therefore, in vivo distribution of Con A was specific for the liver.

Mechanism of Hepatocyte Cell Death in Con ATreated Mice. We wondered which mechanisms are likely to underlie Con $\mathrm{A}$-induced hepatocyte death in vivo. Therefore, livers of mice treated with Con A were histologically examined. Infiltration of neutrophils and agglutinated erythrocytes were observed in livers of mice no later than 3.5 hours after treatment with 20 $\mathrm{mg} / \mathrm{kg}$ of Con A. Eight hours after Con A injection, numerous intracellular DNA-containing apoptotic bodies were detectable as well as karyorrhexis and diffuse cloudy swelling in the hepatocellular cytoplasm (Fig. 2). However, nuclear chromatin condensation was not observed. The formation of apoptotic bodies was noted as early as 3.5 hours after administration of Con A, i.e., at an early point of development of liver injury (not shown). Because only weak signs of necrotic hepatocyte cell death were observed histologically 8 hours after Con $\mathrm{A}$ administration and because apoptotic alterations preceded development of hepatic lesions as measured by ALT release (not shown, Table 1), apoptotic mechanisms are likely to be involved in the early events of liver injury induced by Con A.

Time Course of Cytokine Release After Con A Challenge. Our previous work showed that NMRI mice challenged by IV administration of $20 \mathrm{mg} / \mathrm{kg}$ Con A released IL-2 into the circulation. ${ }^{12}$ IL-2 production was considered to be a consequence of Con A-induced $\mathrm{T}$ cell activation in vivo. As shown in Fig 3, the cytokines GM-CSF, TNF, and IFN- $\gamma$ were also detectable in plasma of mice treated with Con A. The time course of cytokine release into plasma (Fig. 3 ) showed the following peak concentrations: GM-CSF, $300 \mathrm{pg} / \mathrm{mL}$ at 1.5 hours; TNF, $2,500 \mathrm{pg} / \mathrm{mL}$ at 2 hours; and IL-2, 34,600 $\mathrm{pg} / \mathrm{mL}$ at 4 hours after Con $\mathrm{A}$ administration. The time
Table 1. Pretreatment of Mice With Anti-Murine TNF- $\alpha$ Antiserum Protects Against Con A-Induced Hepatitis

\begin{tabular}{lccc}
\hline \multicolumn{1}{c}{ Treatment } & $\begin{array}{c}\text { ALT } \\
(\mathbf{U} / \mathbf{L})\end{array}$ & $\begin{array}{c}\text { TNF } \\
(\mathbf{p g} / \mathbf{m L})\end{array}$ & $\begin{array}{c}\mathbf{I L - 2} \\
(\mathbf{p g} / \mathbf{m L})\end{array}$ \\
\hline $\begin{array}{l}\text { Solvent control } \\
\text { Con A }\end{array}$ & $40 \pm 20$ & $\leq 20$ & $\leq 100$ \\
$\begin{array}{l}\text { Control antiserum }+ \\
\quad \text { Con A }\end{array}$ & $1,600 \pm 767$ & $175 \pm 36$ & $8,010 \pm 1,530$ \\
$\begin{array}{l}\text { Anti-murine TNF- } \alpha \\
\quad \text { antiserum + Con A }\end{array}$ & $55 \pm 20^{*}$ & $\leq 20$ & $9,020 \pm 2,870$ \\
\hline
\end{tabular}

NOTE. Con A $(20 \mathrm{mg} / \mathrm{kg})$ was intravenously injected. Control sheep antiserum or polyclonal sheep anti-murine TNF- $\alpha$ antiserum wa intravenously administered at a dose of $10 \mu \mathrm{L}$ per mouse in a total volume of $300 \mu \mathrm{L}$ PBS 15 minutes before Con A. ALT was determined 8 hours after Con A challenge. TNF or IL-2 were measured in plasma of the animals 1.5 hours or 4 hours, respectively, after Con $A$ administration. Data are expressed as mean \pm SEM; $n$ $=6$.

$* P \leq .05$ vs. disease control.

course of IFN- $\gamma$ release showed a steady further increase with time. Maximal concentrations, i.e., 2,770 $\mathrm{pg} / \mathrm{mL}$, were measured at the end of the experiment at 8 hours after intervention. Within this time window of 8 hours, Con A-challenged mice developed severe liver injury (Table 1). ${ }^{12}$ The cytokine release pattern seems to be typical for a T-cell response, because IL-2 and IFN- $\gamma$ are typical lymphokines. ${ }^{21}$ At present, we cannot define the cellular origin of GM-CSF or TNF (see below). We also reported previously that macrophages serve as effector cells together with $\mathrm{CD}^{+} \mathrm{T}$ cells in liver failure induced by Con A. ${ }^{12}$ Antigen-presenting macrophages are known to release IL-1 in order to activate T-helper cells for the respective immune response. Therefore, we measured IL-1 production after in vivo treatment of mice by Con A. Because mouse plasma was cytotoxic towards the D10N cells used in the IL-1 bioassay, we were not able to determine circulating IL-1. To overcome this problem we chose a different approach: at different time points after in vivo challenge of mice with $20 \mathrm{mg} / \mathrm{kg}$ Con A, we prepared spleens and determined cytokine contents ex vivo by assaying cytokine concentrations in the supernatants of these cell suspensions. The following maximum concentrations were found: IL- $1 \alpha, 9,590 \mathrm{pg} / \mathrm{mL}$ at 3 hours; GMCSF, $120 \mathrm{pg} / \mathrm{mL}$ at 1 hour; TNF, 3,600 pg/mL at 1 hour; and IL-2, $47,500 \mathrm{pg} / \mathrm{mL}$ at 4 hours after Con $\mathrm{A}$ challenge.

The Contribution of TNF-a to Con A-Induced Liver Injury. TNF has been identified as a central mediator in experimental macrophage- or T-cell-dependent infectious disease models such as endotoxin shock, ${ }^{22}$ gram-negative, ${ }^{23}$ and gram-positive sepsis ${ }^{24}$ as well as in endotoxin-induced hepatitis in galactosamine-sensitized mice. $^{25}$ The capacity of Con A to stimulate TNF release in vivo prompted us to investigate the effect of an anti-TNF antiserum on Con $A$ challenge. The results in Table 1 show that pretreatment of mice by polyclonal sheep anti-mouse TNF- $\alpha$ antiserum fully protected 
cation of cachectin, a lipoprotein lipase-suppressing hormone secreted by endotoxin-induced RAW 264.7 cells. J Exp Med 1985; 161:984-995.

39. Elliott JF, Lin Y, Mizel SB, Bleackley RC, Harnish DG, Paetkau V. Induction of interleukin-2 messenger RNA inhibited by Cyclosporine A. Science 1984;226:1439-1441.

40. Espevik T, Figari IS, Shalaby MR, Lackides GA, Lewis GD, Shepard HM, Palladino MA Jr. Inhibition of cytokine production by Cyclosporine $A$ and transforming growth factor $\beta$. J Exp Med 1987; 166:571-576.

41. Remick DG, Nguyen DT, Eskandari MK, Strieter RM, Kunkel SL. Cyclosporine A inhibits TNF production without decreasing TNF mRNA levels. Biochem Biophys Res Commun 1989; 161:551-555.

42. Kinkhabwala M, Sehajpal P, Skolnik E, Smith D, Sharma VK, Vlassara H, Cerami A, et al. A novel addition to the T cell repertory. Cell surface expression of tumor necrosis factor/cachectin by activated normal human T cells. J Exp Med 1990;171:941946.

43. Aversa G, Punnonen J, de Vries JE. The 26-kD transmembrane form of tumor necrosis factor $\alpha$ on activated $\mathrm{CD} 4^{+} \mathrm{T}$ cell clones provides a costimulatory signal for human $B$ cell activation. J Exp Med 1993;177:1575-1585.

44. Liu CC, Detmers PA, Jiang S, Young JDE. Identification and characterization of a membrane-bound cytotoxin of murine cytolytic lymphocytes that is related to tumor necrosis factor/ cachectin. Proc Natl Acad Sci USA 1989;86:3286-3290.

45. Kriegler M, Perez C, DeFay K, Albert I, Lu SD. A novel form of TNF/cachectin is a cell surface cytotoxic transmembrane protein: ramifications for the complex physiology of TNF. Cell 1988; 53:45-53.

46. Sun D, Wekerle H. Ia-restricted encephalitogenic T lymphocytes mediating EAE lyse autoantigen-presenting astrocytes. Nature 1986;320:70-72.

47. Beutler B, Cerami A. Tumor necrosis, cachexia, shock, and inflammation: a common mediator. Annu Rev Biochem 1988; 57:505-518.

48. Vey E, Zhang J-H, Dayer J-M. IFN- $\gamma$ and 1,25(OH)2D3 induce on THP-1 cells distinct patterns of cell surface antigen expression, cytokine production, and responsiveness to contact with activated T cells. J Immunol 1992;149:2040-2046.

49. Cannistra SA, Vellenga E, Groshek P, Rambaldi A, Griffin JD. Human granulocyte-monocyte colony-stimulating factor and interleukin 3 stimulate monocyte cytotoxicity through a tumor necrosis factor-dependent mechanism. Blood 1988;71:672-676.

50. Sisson SD, Dinarello CA. Production of interleukin-1 $\alpha$, interleu- kin-1 $\beta$ and tumor necrosis factor by human mononuclear cells stimulated with granulocyte-macrophage colony-stimulating factor. Blood 1988;72:1368-1374.

51. Koerner TJ, Adams DO, Hamilton TA. Regulation of tumor necrosis factor (TNF) expression: interferon- $\gamma$ enhances the accumulation of mRNA for TNF induced by lipopolysaccharide in murine peritoneal macrophages. Cell Immunol 1987;109:437443.

52. Collart MA, Belin D, Vassalli JD, Dekossodo S, Vassalli P. Gamma interferon enhances macrophage transcription of the tumor necrosis/cachectin, interleukin-1, and urokinase genes, which are controlled by short-lived repressors. J Exp Med $1986 ; 163: 2113-2118$

53. Jacob CJ, Holoshitz J, Van der Meide P, Stober S, McDevitt HO. Heterogenous effects of IFN- $\gamma$ in adjuvant arthritis. J Immunol 1989; $142: 1500-1505$.

54. Billiau A, Heremans H, Vandekerckhove F, Dillen C. Anti-interferon- $\gamma$ antibody protects mice against the generalized Shwartzman reaction. Eur J Immunol 1987; 17:1851-1854.

55. Heinzel FP. The role of IFN- $\gamma$ in the pathology of experimental endotoxemia. J Immunol 1990; 145:2920-2924.

56. Grau GE, Heremans H, Piguet PF, Pointaire P, Lambert P-H, Billiau A, Vassalli P. Monoclonal antibody against interferon $\gamma$ can prevent experimental cerebral malaria and its associated overproduction of tumor necrosis factor. Proc Natl Acad Sci USA 1989;86:5572-5574.

57. Tiegs G, Barsig J, Matiba B, Uhlig S, Wendel A. Potentiation by GM-CSF of LPS toxicity in mice. J Clin Invest 1994;93:26162622.

58. Owen-Schaub LB, Crump III WL, Morin GI, Grimm EA. Regulation of lymphocyte tumor necrosis factor receptors by IL-2. J Immunol 1989; 143:2236-2241.

59. Fraker DL, Langstein HN, Norton JA. Passive immunization against tumor necrosis factor partially abrogates interleukin 2 toxicity. J Exp Med 1989;170:1015-1020.

60. Movat HZ, Burrowes CE, Cybusky MI, Dinarello CA. Acute inflammation and a Shwartzman-like reaction induced by interleukin-1 and tumor necrosis factor. Synergistic actions of the cytokines in the induction of the inflammation and microvascular injury. Am J Pathol 1987; 129:463-476.

61. Everaerdt B, Brouckaert P, Shaw A, Fiers W. Four different interleukin-1 species sensitize to the lethal action of tumor necrosis factor. Biochem Biophys Res Commun 1989;163:378-385.

62. Grau GE, Lambert P-H, Vassalli P, Piguet P-F. Tumor necrosis factor/cachectin as an effector of T cell-dependent immunopathology. Int Rev Exp Pathol 1993;34B:159-171. 